information on matters such as agreeing routine and emergency procedures with local authority staff, the organization and training of On-Call Medical Officers, and the maintenance of good relationships with councillors.

This book will be welcomed by younger community physicians and clinical medical officers. Their older colleagues will find it of value in checking their own standards of work.

The Prevalence of Illness in Childhood. A Report of the British Births Child Study into Illnesses and Hospital Experiences of Children during the First Three and a Half Years of Life

By R. N. Chamberlain and R. N. Simpson. Pp. $x+142$, illustrated. Pitman Medical in association with The Fellowship of Postgraduate Medicine, 1979. £15.00.

This book is a follow-up report on 17196 births surveyed during one week in April 1970. From these births, a $10 \%$ random sample was taken excluding unmarried, divorced, separated and widowed mothers which left a sample of 1609 children of whom 30 had already died by 1972. Questionnaires were largely completed by medical officers of recall information from parents providing details on 1098 children up to the age of 3 years and it is this information that forms the basis of the report.

Much of the information being retrospective and from a population that excludes the children at greatest disadvantage, must be both incomplete and biased and thus it would be dangerous to draw too many conclusions from the findings.

The main points would seem to be the following. Except for rubella, the presence of a sibling has a greater influence on infection rate than does social class and this particularly applied to measles in the pre-school child. Children sleeping with their parents are more likely to have a respiratory tract infection requiring hospital admission. Maternal smoking causes a significant increase in lower respiratory tract infections in children and this is directly related to the amount that the mother smokes.

The number and severity of accidents is directly related to mothers being at work and to the amount of time she is at work, and being more so when the mothers are at full-time than at part-time work.

The morbidity rate among children was difficult to assess and the authors considered this was under-reported. Thirtynine per cent. of children had attended out-patients in the first 3 years and $20 \%$ had been admitted to hospital. Presented in another way, $57 \%$ of boys and $47 \%$ of girls had attended hospital either as an in-patient or an out-patient by the age of 3.5 years.

One in 50 children were said by the mothers to have lost consciousness between the age of one month and 3 years, the commonest cause being head injury but not all children had been taken for medical care.

Of the 118 children who had died, 110 were traced and, of these, $76 \%$ had had post-mortems. Forty-three had died as cot deaths at home or on the way to hospital, and 64 in hospital. Two had been road accidents. The congenital deformity rate for the cohort was 2.4 per thousand live births and, for unexpected deaths, $2 \cdot 1$ per thousand. Of the 35 children who were finally diagnosed as sudden infant death syndrome, 12 were said to have had no symptoms before death.

Perhaps the most clinical aspect of the report lies in the comments on the ineffectiveness of screening. The current statistics of the over-all incidence of congenital anomalies at birth were considered useless for comparison of one population with another except perhaps in the field of cleft lips and palate and gross CNS deformities. The authors feel that the current screening for squints, hearing, speech, etc., are inadequate and some may be creating more worry to parents than the benefit of early diagnosis.

This book should be read by all those concerned with plan- $\frac{2}{c}$ ning primary child care services, but as a source of accurate $€$ data on morbidity it is of limited value owing to the retrospective nature of the information, the incompleteness of the ? population studied and the selection of a single week's births for cohort study.

\section{Progress in Neurological Research}

Edited by Peter O. Behan and F. Clifford Rose. Pp. 232, ఓొ illustrated. Pitman Medical Publishing, Kent, 1979.£16.00.

The main title of this book is slightly misleading as it is $\vec{\omega}$ chiefly about research in motor neurone disease-amyotrophic lateral sclerosis. Unfortunately, the amount of re-search being done on motor neurone disease is little compared $\frac{0}{3}$ to that on many other neurological diseases, so in order to have a reasonable amount to put in a book costing $£ 16$ one $G$ has to spread the net to involve virology and immunology. Nevertheless, it is this type of book which helps to bring together advances in motor neurone disease and encourages further research. There is a good section on virology which discusses the relationship between viruses and poliomyelitis, motor neurone disease and multiple sclerosis.

It is interesting how the jejunal biopsy can so often demon-윽 strate abnormal virological findings in chronic neurological $\rightarrow$ disease. The group from Brooklyn who have found viruses $>$ in the jejunum of patients with motor neurone disease discuss the treatment of one patient with adenine arabinoside and another with human fibroblast interferon. They repopt $\vec{\theta}$ an improvement in the clinical condition of both patients. Three cases of mycosis fungoides with motor neurome disease are reported from Glasgow.

Clinical, genetic, neurophysiological and histologicư⿰亻 aspects of motor neurone disease are discussed. The book ends with a description of neurological diseases in animals $\bar{D}$ which can act as models for this disease in man.

This book is helpful to anyone considering research in $\mathbb{D}$ motor neurone disease and should be part of the library of neurological departments involved in research.

\section{Progress in Stroke Research 1.}

Edited by Roger M. Greenhalgh and F. Clifford Rose. Pp. 420, illustrated. Pitman Medical Publishing, Kent, 1979. £22.50.

Strokes are so common that no clinician can practise without meeting them, and the laboratories and paramedical staff $\bar{\varnothing}$ spend much time doing tests on or helping those with this affliction. Research into strokes is continuing on many fronts and there is much in this book to interest not only 음 neurologists, physicians and vascular and neuro-surgeons but also radiologists, pathologists and pharmacologists.

The chapters vary considerably in their quality (and length). Some cover work several years old and accepted in general $N$ consensus views of the subject, while others give ideas up to $G$ the limits of our present knowledge. If this is only volume $\mathrm{N}$ I, volume II will have to be more topical and up-to-date than the older, less progressive aspects would have been completed $\omega$ in volume $I$.

The probability of developing a carotid stenosis and 0 arterial disease (excluding intracranial aneurysms) is very $\frac{2}{\square}$ dependent on factors which we can prevent. Heavy smokers $\stackrel{\$}{\$}$ are recommended to read Chapter 2.

Thompson from Dallas, Texas, sets a reasoned regime for dealing with asymptomatic carotid bruits. If non-invasive screening techniques using the Doppler effect, show significant 
narrowing, the patient is considered for arteriography. This is only done when there would be no contra-indication to operation. Thompson makes a good case for operating even when the patient is asymptomatic, as the chances of the patient developing symptoms later are very great.

The cumulative number system of classification (Chapter 17) as applied to stroke is an interesting concept which, if it could be more universally accepted, would allow multi-centre trials to be more easily organized and elucidated. Clinical trials of various forms of management are discussed. There is also an interesting series of chapters on non-invasive assessment of carotid artery disease. The book ends with a series of papers on intracranial surgery for stroke which is a form of therapy that is developing rapidly and may become increasingly used.

This book can be recommended to the wide range of doctors who are involved in the management of patients with strokes.

\section{Treatment of Common Acute Poisonings (4th edn)}

By H. Matthew and A. A. H. Lawson. Pp. $x+210$. Churchill Livingstone, Edinburgh, London and New York. $£ 6.00$.

When the first edition of this book appeared in 1967 there is no doubt, as the authors emphasize, that dangerous misconceptions about the management of acute poisonings were rife. But a fresh outlook was already being directed to the subject, notably by Clemmesen in Denmark and by Lockit in England. Building on this basis the Edinburgh team under Matthew thoroughly integrated the philosophy for the clinician and, as a result, a more enlightened attitude not only spread but was also profitably adopted.

Today that proselytizing is no longer imperative and the pragmatic sermon has less of a place. Rather should there be a consolidation; with guidance to the audience in the direction of the latest advances that appear to be promising for practice. In this light, parts of this latest fourth edition parade somewhat self-consciously. Thus, with the statistics, surely the graph of admissions to the Royal Infirmary, Edinburgh (progressively taller and narrower each time it is reproduced) has become a little out of date, ending as it does in 1973. Much more recent and relevant figures are obtainable, nationally too, which almost impertinently reveal that, for all our efforts, the overall deaths from poisoning remain unchecked over recent decades. And whilst the barbiturates have retreated in the face of righteous pressure the antidepressants have just as adequately taken their place as 'captains of the toxic men of death'.

Similarly, the section on the place of the laboratory includes some generalizations, not merely about analysis but also about pharmacokinetics and pharmodynamics that hardly withstand measured criticism.

Then the final chapters on drug addiction and prevention are, sadly, little more than perfunctory. Either these topics should be tackled resolutely and in an informed manner or, perhaps better still in a small book, omitted altogether.

Harsh as some of this criticism may appear it is confined to a relatively small part of the work. The clinical sections making up the bulk of the text are still very worthwhile and any doctor who wants to keep himself informed of acute poisoning in the practical sense could do no better than keep this volume by him. 